Illinois State University

ISU ReD: Research and eData

Theses and Dissertations

3-5-2019

\title{
The Role Of Perceived Academic Control, Preoccupation With Failure, And Academic Emotions On Major Satisfaction
}

Alison N. Lehman

Illinois State University, alison.lehman@outlook.com

Follow this and additional works at: https://ir.library.illinoisstate.edu/etd

Part of the Education Commons, and the Psychology Commons

\section{Recommended Citation}

Lehman, Alison N., "The Role Of Perceived Academic Control, Preoccupation With Failure, And Academic Emotions On Major Satisfaction" (2019). Theses and Dissertations. 1105.

https://ir.library.illinoisstate.edu/etd/1105

This Thesis is brought to you for free and open access by ISU ReD: Research and eData. It has been accepted for inclusion in Theses and Dissertations by an authorized administrator of ISU ReD: Research and eData. For more information, please contact ISUReD@ilstu.edu. 
THE ROLE OF PERCEIVED ACADEMIC CONTROL, PREOCCUPATION WITH FAILURE, AND ACADEMIC EMOTIONS ON MAJOR SATISFACTION

\section{ALISON N. LEHMAN}

\section{Pages}

This thesis reports the results of a study exploring how preoccupation with failure, perceived academic control, and academic emotions are associated with students' major satisfaction. The responses of 391 college students to an online survey revealed that academic emotions and perceived academic control were significantly related to major satisfaction. Even after controlling for year in school and the overlap of students' interests with the content of their majors, academic control and academic emotions still remained significant predictors of major satisfaction, which provides counselors and college professors possible intervention points to target major satisfaction. The results also revealed a significant interaction between year in school and positive emotions on major satisfaction, with emotions having a weaker association with major satisfaction as year in school advanced. Anxiety partially mediated the effect of academic control on major satisfaction. Contrary to hypothesis, preoccupation with failure did not have a curvilinear relationship with major satisfaction, although in some analyses it had a significant positive linear association. Limitations and future directions are discussed. KEYWORDS: Perceived academic control; College students; Major satisfaction; Preoccupation with failure; Academic emotions 
THE ROLE OF PERCEIVED ACADEMIC CONTROL, PREOCCUPATION WITH FAILURE, AND ACADEMIC EMOTIONS ON MAJOR SATISFACTION

\author{
ALISON N. LEHMAN
}

\begin{abstract}
A Thesis Submitted in Partial Fulfillment of the Requirements for the Degree of MASTER OF SCIENCE

Department of Psychology ILLINOIS STATE UNIVERSITY
\end{abstract}


Copyright 2019 Alison N. Lehman 
THE ROLE OF PERCEIVED ACADEMIC CONTROL, PREOCCUPATION WITH FAILURE, AND ACADEMIC EMOTIONS ON MAJOR SATISFACTION

ALISON N. LEHMAN

COMMITTEE MEMBERS:

Margaret N. Nauta, Chair

Daniel G. Lannin 


\section{ACKNOWLEDGMENTS}

I would like to thank my committee members, Drs. Margaret M. Nauta and Daniel G.

Lannin for their support and guidance in developing and revising multiple drafts to complete a comprehensive research project. I would also like acknowledge my family and friends who continually support my dreams and passions in life.

A. N. L. 


\section{CONTENTS}

Page

ACKNOWLEDGMENTS

$\begin{array}{ll}\text { CONTENTS } & \text { ii }\end{array}$

TABLES iv

FIGURES

$\begin{array}{lc}\text { CHAPTER I: INTRODUCTION } & 1\end{array}$

CHAPTER II: LITERATURE REVIEW

Previous Research

The Challenge and Importance of Choosing a Satisfying Academic Major 6

Perceived Academic Control in Performance $\quad 12$

Academic Emotions related to Perceived Control 14

Academic Emotions in Academic Outcomes 15

Perceived Academic Control and Preoccupation with Failure $\quad 21$

Possible Developmental Shifts in Predictors of Academic Major Satisfaction 22

Relevant Theories

$\begin{array}{ll}\text { Attribution Theory } & 8\end{array}$

Control-Value Theory on Academic Emotions 13

$\begin{array}{ll}\text { Action Control Theory } & 18\end{array}$

Defining Constructs

Perceived Academic Control 11

$\begin{array}{ll}\text { Academic Emotions } & 14\end{array}$

$\begin{array}{ll}\text { Preoccupation with Failure } & 20\end{array}$ 
Perceived Academic Control and Preoccupation with Failure $\quad 21$

Purpose of this Study and Hypotheses $\quad 24$

$\begin{array}{ll}\text { CHAPTER III: METHOD } & 28\end{array}$

$\begin{array}{ll}\text { Participants } & 28\end{array}$

$\begin{array}{ll}\text { Measures } & 29\end{array}$

$\begin{array}{ll}\text { Academic Control } & 29\end{array}$

Positive and Negative Emotions $\quad 29$

Academic Emotions (Boredom and Anxiety) 30

Preoccupation with Failure $\quad 32$

Major Satisfaction $\quad 33$

Demographic, Control, and Validation Items 33

$\begin{array}{ll}\text { Procedure } & 34\end{array}$

CHAPTER IV: RESULTS

CHAPTER V: DISCUSSION 45

$\begin{array}{ll}\text { Practical Implications } & 50\end{array}$

Limitations and Future Research Directions $\quad 51$

$\begin{array}{ll}\text { Conclusions } & 53\end{array}$

$\begin{array}{ll}\text { REFERENCES } & 55\end{array}$ 


\section{TABLES}

Table

Page

1. Means, Standard Deviations, and Correlations among the Measures

2. Results of Hierarchical Linear Regression Analysis Testing Predicted Curvilinear Relationship between Preoccupation with Failure and Major Satisfaction

3. Results of Hierarchical Linear Regression Analyses Predicting Major Satisfaction based on Academic Control and Preoccupation with Failure

4. Results of Hierarchical Linear Regression Analyses Predicting Major Satisfaction based on All Study Variables and Interactions with Year in School

5. Conditional Effects of Year in School on Major Satisfaction 


\section{FIGURES}

Figure Page

1. Path Analysis of the Mediating Effect of Anxiety in the Relationship of Academic Control and Major Satisfaction 


\section{CHAPTER I: INTRODUCTION}

While rates of matriculation into higher education are increasing, the large number of students who do not obtain a college degree in a timely manner is of concern because attending college without completing a degree is financially burdensome for students and their families. The number of students who enrolled in degree-granting undergraduate institutions after high school increased from 13.2 to 18.1 million between the years of 2000 and 2010, and the number of students who will enroll in undergraduate programs is predicted to increase to 20.6 million by the year 2021 (Aud et al., 2012). While the upward trend of students enrolling in higher education can initially appear promising, this figure hides significant variation in the outcomes of those students. Nearly $85 \%$ of students who graduated from high school after 2004 had some form of experience in college (McPherson, Ferguson, \& Fanton, 2016). However, among students who began their studies in the fall of 2009, the six-year graduation rate was only $53 \%$ (Shapiro et al., 2015).

Low academic major satisfaction is also a known risk factor for college drop-out intentions in part because it can affect motivation and study behaviors, leading to poor performance (Suhre, Jansen, \& Harskamp, 2007). It is common for students to leave higher education prior to degree completion because of financial hardship and various life circumstances, such as increasing family obligations or unexpected emergencies (Public Agenda, 2009). Even if low satisfaction does not lead students to leave college altogether, low satisfaction is associated with changing majors (Nauta, 2010), something that approximately $50 \%$ to $75 \%$ of students do over the course of their undergraduate careers (Gordon, Habley, \& Grites, 2008; Porter \& Umbach, 2006). Changing to a major that is a better fit with a student's interests, abilities, or career goals is sensible because it can lead to a more satisfactory career 
(e.g., Bowling, Eschleman, \& Want, 2010), but depending on when students decide to change their majors, this can impact the amount of additional time required to complete new course requirements. Even one major change, if it occurs late in the student's education, can prolong the time to graduation. Additional time in college impacts students' finances by delaying entry into the workforce and requiring them to pay tuition for the additional credit hours.

The adverse consequences of low major satisfaction, especially if students have already invested significant time in the major, have made it a construct of importance to those interested in helping to address the problem of low higher-education completion rates. Understanding more about precursors of major satisfaction would allow for the early identification of students who are at risk for non-completion of degrees, facilitate the development of interventions that may reduce college drop-outs, and in situations where a change of majors is warranted make it more likely that the change occurs early enough to allow students to graduate in a timely manner.

Considerable research has investigated academic major satisfaction from the perspective of institutional characteristics, such as the quality of course instruction, the array of course offerings, faculty-student relationships, and opportunities for out-of-class engagement in activities related to the major (e.g., Courts, Lounsbury, Saudargas, \& Tatum, 2000; Marks, Haug, \& Huckabee, 2016). But within any given major at a given institution some students are satisfied, and others are not, suggesting student factors also play a large role in major satisfaction.

Congruence between a student's interests and his or her academic major is the primary student factor that has been a focus of research to better understand major satisfaction. Tracey and Robbins (2006) found that congruence between a chosen major and students' interests was 
a better predictor of academic success after five years than the use of ACT scores. Also, students whose interests are congruent with their college major tend to have higher academic satisfaction and intentions to complete their degree (Schmitt, Oswald, Friede, Imus, \& Merritt, 2008). When a student has low congruence with his or her major, a change of major is the recommended course of action, as counseling interventions are unlikely to attempt to or be successful at changing a student's interests or academic abilities.

The purpose of the current study is to understand the associations that perceived academic control, academic emotions, and preoccupation with failure may have with students' major satisfaction. Other student factors besides interest congruence may also be associated with major satisfaction, but there is little research investigating these possibilities. These student variables have appeal for guiding interventions designed to increase major satisfaction because, unlike abilities and interests, they could easily be targeted by counselors who could teach students new strategies for coping with anxiety or work with them to recognize aspects of their academics over which they have personal control. For example, Perry et al. (2005) found that attributional retraining can lead to an increase in perceptions of control over situations and increase students' overall academic performance. Such interventions do not necessarily require a change of majors, which is appealing for cases where low congruence is not accounting for low major satisfaction or when the student is already well-advanced in the major and resistant to changing majors.

A recent study (Respondek, Seufert, Stupnisky, \& Nett, 2017) linked perceived academic control and academic emotions to indicators of academic success, including their drop-out intentions. In regard to the academic setting, Perry et al. (2005) defined perceived academic control as a student's perceived understanding of his or her impact on academic 
outcomes, and Pekrun, Frenzel, Goetz, and Perry (2007, p. 15) defined academic emotions as the emotions that are connected "directly to achievement activities or achievement outcomes." The authors found that low perceived academic control and the academic emotions of enjoyment, boredom, and anxiety were all potential risk factors for intentions to leave college prior to earning a degree. The results also revealed that anxiety (but not the other academic emotions) fully mediated the association between perceived academic control and students' dropout intentions. However, the study was conducted only with first- and second-year students attending a university that specialized in science, technology, engineering, and math. The degree to which these variables are important in the experiences of students in other types of majors and years in school is unknown, and it is also not known whether these student variables are related to academic major satisfaction. Although major satisfaction and drop-out intentions are related, drop-out intentions can be influenced by many factors (e.g., financial) that are unlikely to affect major satisfaction, so studying major satisfaction as a separate outcome variable would be helpful.

The proposed study will extend the Respondek et al. (2017) study that measured students' drop-out intentions in that it focuses on perceived academic control and academic emotions. Bean (1985) found that dropout intention was hard to measure due to tracking students who change their major, leave the university for a different school, or terminate their studies altogether. Instead of using the outcome measure of drop-out intention, therefore, this proposed study will measure students' global satisfaction with their choices of college majors as the outcome variable of interest. This proposed study will also examine the associations of perceived academic control and academic emotions to major satisfaction among students with a wide array of majors and all years in school instead of the more narrow sample studied by 
Respondek et al. Finally, the proposed study will examine a third student factorpreoccupation with failure - that, as discussed later, theoretically might interact with perceived academic control in the prediction of major satisfaction. In the academic setting, Perry et al. (2001) referred to preoccupation with failure as the focus on the negative, stressful event of failure (Perry et al., 2001). 


\section{CHAPTER II: LITERATURE REVIEW}

This chapter begins with an explanation of the importance of students finding a satisfying academic major and why doing so can be challenging. The chapter then examines prior research on factors that influence college students' academic success in general. Transition to higher education can be a challenging task in and of itself and has been the focus of various researchers to better understand factors that lead to academic success and dropout intention. The theories and concepts outlined in this paper are attribution theory on perceived academic control, control-value theory on academic emotions, and action control theory on preoccupation with failure. I will discuss how the concepts of perceived academic control, academic emotions, and preoccupation with failure that are derived from the theories mentioned above play a role in students' understandings of their successes and failures, and the degree to which students focus on the feedback from their academic failures that in turn can influence their academic major satisfaction. While there is little known research about major satisfaction and the link to perceived academic control, academic emotions, and preoccupation with failure, I will discuss how perceived academic control, academic emotions, and preoccupation with failure might have similar impacts on major satisfaction as they do for academic success in general.

\section{The Challenge and Importance of Choosing a Satisfying Academic Major}

Some students begin their studies at an undergraduate university with a clear vision of their intended major and future career, but those students are the minority, as most undergraduates change majors at least once (Gordon, Habley, \& Grites, 2008; Porter \& Umbach, 2006). The typical student is either undecided about a major when matriculating into an institution or experiences a change of heart about a previously declared major. It is not 
surprising that many students have difficulty choosing majors or initially enter majors that they find unsatisfactory. The transition from high school to higher education can be complex with increased responsibility, more autonomy, and new roles. For many students, choosing a college major can be one of their first experiences in making an independent, long-term decision which may lead to their future career path (Galotti et al., 2006). Decisions about academic majors are also very complex because of the array of factors that must be considered. Research suggests students take into consideration many sources of information, including job characteristics, interest in the subject, and major characteristics (Beggs, Bantham, \& Taylor, 2008). For example, students report considering their career goals, their personal abilities, parents' prior education and career path, starting salary and potential job opportunities, cost of undergraduate studies, time commitment, family expectations, financial situation, professors' suggestions, and various other considerations (Galotti et al., 2006). The complexity of the decision could lead some students to rely on the influence of peers or parents and their assumptions about various majors rather than focusing on their own career goals and values (Beggs, Bantham, \& Taylor, 2008).

The importance of navigating the complexity of choosing a major and finding one that a student is satisfied with is well documented. During a student's undergraduate studies, satisfaction with their chosen major can have a positive effect on their motivation and study behaviors, which impacts their overall academic accomplishments (Suhre, Jansen, \& Harskamp, 2007). After completion of their degree, students usually select a career path based on their area of study during college; the intent is to achieve a job that aligns with their interests and skills (Suhre et al., 2007). Job satisfaction is positively related to subjective wellbeing, which stresses the importance of choosing a suitable major that will lead to future career 
satisfaction (Bowling, Eschleman, \& Want, 2010). Therefore, a chosen college major can have an impact that lasts beyond a student's undergraduate academic success and satisfaction.

Counselors have several theories (e.g., Dawis, 1994; Holland, 1997; Super, 1956) and much empirical literature that can guide interventions for students who are having difficulty choosing a major or who are dissatisfied with their current majors. Interventions typically involve helping students to learn about themselves and the world of work so that they can make an informed decision and find a major that is a good fit (i.e., congruent) with their interests, skills, and values. Less is known about how to work with students who have low academic major satisfaction that cannot be attributed to low congruence. The present study examines other factors that may affect major satisfaction and that therefore could be logical targets of counseling interventions. As described below, these factors are drawn from Attribution Theory, Control-Value Theory, and Action Control Theory.

\section{Attribution Theory}

In the 1960s and 1970s, research in the field of psychology started to focus on cognitions, which formed the basis for the field of social cognition (Dweck, 2018). Out of cognition research, a common drive was identified that individuals use to make inferences about others' behaviors. Gestalt psychologist Fritz Heider cultivated the attribution theory to further understand how individuals explain the causes of others' behaviors (Griffen, 2011). Heider suggested that attributions were a three-step process: perception of the action, a judgement of the intention of the action, and an attribution of disposition back to the individual doing the action (Griffen, 2011).

Heider proposed that the determinants of behavior could be assessed by an individual's ability, the difficulty of the task at hand, and the amount of exerted effort (Malle, 2011; 
Weiner, 2010). Further building onto his theory, Heider coined the concepts of internal and external attributes that would continue to influence the field of social cognition; these concepts were proposed to enhance the explanation of the causes of situations and behaviors (Malle, 2011; Weiner, 2010). External attribution refers to the process of interpreting the cause of an individual's behavior to a situational factor that is outside an individual's control (Weiner, 2010). On the other hand, internal attribution refers to the process of interpreting the cause of a behavior to something about the individual him- or herself (Weiner, 2010). When behavior is explained through an internal attribute, the attribute is usually an enduring internal characteristic, such as a personality characteristic or motives (Weiner, 2010).

Around the same time Heider developed the attribution theory, Julian Rotter constructed the social-learning theory to explain how individuals understand their own behaviors (Weiner, 2010). Rotter proposed that the locus of control is a belief system that individuals hold about sources for outcomes; the locus of control comprises an internal and external locus of control, which was similar to Heider's ideas of internal and external attributes (Weiner, 2010). An individual engages in an internal locus of control with the belief that he or she has control over his or her own outcomes, such as through the use of skill and ability (Weiner, 2010). An individual engages in an external locus of control with the belief that his or her behaviors are influenced by factors outside of his or her control, such as luck and chance (Weiner, 2010).

To further develop the attribution theory, Weiner expanded the idea of how individuals attribute the successes and failures of their own actions (Weiner et al., 1971). For many individuals, the process of creating causal explanations from successes and failures is automatic and often goes unnoticed. However, causal attributions can be viable in helping 
individuals adapt to changing environments around them (Snead et al., 2015; Weiner, 1982). Building on the theories of Heider and Rotter, Weiner developed a three-dimensional model of attributions: locus of control, stability, and causal control (Weiner, 2010). As proposed by Rotter, locus of control can be attributed to either an internal attribute (the individual has control over their outcomes) or an external attribute (outside factors control the outcomes for the individual; Malle, 2011; Weiner, 2010). The stability of attributions refers to whether the cause of the outcome is likely to change or remain constant and endure (Weiner, 2010). Causal control of attributions refers to whether an individual has control over an event or not.

Building from Heider's proposed determinants for behavior, Weiner further proposed that there are four determinants of behavior: ability, task difficulty, luck, and effort (Weiner, Frieze, Kukla, Reed, Rest \& Rosenbaum, 1971). These four determinants explain how the individual uses available information to understand his or her successes and failures, and these successes and failures can be further analyzed through locus of control and stability. Ability refers to the degree of past success an individual faced in a certain situation or similar tasks; ability can be viewed as being stable and attributed to an internal locus of control (Weiner et al.). Task difficulty can be inferred from social norms that indicate the performance difficulty of a task; for example, if many individuals succeed at a task, the task difficulty is usually rated as easy (Weiner et al.). Task difficulty can be defined as stable and attributed to an external locus of control. Luck is a pattern, usually random, of prior reinforcement; luck can be defined as unstable and attributed to an external locus of control (Weiner et al.). Finally, effort looks at the outcome information to determine how hard an individual tried; effort can be defined as unstable and attributed to an internal locus of control (Weiner et al.). 
Perceived Academic Control. In the attribution theory, Weiner stated that individuals use available information to understand their success and failures; similarly, college students search within themselves and their academic context to understand their academic successes and failures (Perry, Hall, \& Ruthig, 2005; Weiner, 2010). Thompson (2002) defined perceived control as an internal locus of control that influences perceived capability to influence events. In an academic setting, perceived academic control refers to a student's perceived understanding of his or her impact on academic outcomes (Perry et al., 2005). For example, a student who attributes his or her success to effort (internal and controllable), will likely perceive his or her performance on that task and similar future tasks as dependent on effort. This attribution of success to effort can equate to higher levels of perceived academic control and lead to greater academic performance (Perry et al., 2005; Thompson, 2002; Weiner, 2010). On the other hand, a student who attributes his or her success to luck (external and not controllable), may adopt a fatalist approach to exams and not exert effort in studying.

Selecting a college major, finding one's place in college, and learning how to be successful academically can be stressful challenges that threaten a student's sense of control (Fishman \& Husman, 2016). A study conducted by Tobin and Raymundo (2010) found that students who presented uncertainty in their ability to determine the cause of their academic successes and failures experienced increased maladaptive attributions and decreased overall well-being. This finding presents the idea that students who feel capable of determining the cause of their academic success and failures may have elevated perceived academic control and motivation to understand their successes and failures (Tobin \& Raymundo, 2010).

Research has found that appraisal of factors that contribute to one's performance can serve as self-protective factors (Perry, Stupnisky, Daniels, \& Haynes, 2008). When elevated, 
the factor of perceived control over one's outcomes can lead to an increase in motivation, performance, and achievement (Perry et al., 2008). Perceived control of the present situation has also been found to lead to better personal adjustment after the occurrence of a stressful events and has also been found to reduce anxiety (Frazier et al., 2011; Frazier, Steward, \& Mortensen, 2004; Perry et al., 2005; Skinner, 1996). Additionally, higher levels of perceived control over life situations leads to increased mental and physical health and overall life satisfaction (Skinner, 1996).

In academic settings, research has found that students who presented with decreased levels of perceived academic control had a greater chance of dropping their current courses (Parker, Perry, Chipperfield, Hamm, \& Pekrun, 2017; Perry, Hladkyj, Pekrun, Clifton, \& Chipperfield, 2005). This increased risk of dropping current courses can also lead to students discontinuing their academic studies by withdrawing from their university (Perry et al., 2005). Finally, Respondek et al. (2017) found that students who presented higher levels of perceived academic control self-reported decreased intentions of withdrawing from their studies.

Regarding academic performance, research has, in fact, found that elevated levels of perceived academic control are related to overall academic success, enhanced effort in academia, and higher levels of intrinsic motivation (Graunke \& Woosley, 2005; Perry, Hladkyj, Pekrun, \& Pelletier, 2001; Respondek et al., 2017; Skinner, 1996). When students are faced with academic failures and challenges, those with elevated levels of perceived academic control tend to have enhanced coping skills (Perry et al., 2001; Skinner, 1996). Additionally, when academic setbacks are viewed and explained as an insufficient amount of exerted effort, this attribution of insufficient effort can help develop ideas of competency and establish a plan for future responses to failure (Smiley, Buttitta, Chung, Dubon, \& Chang, 2016). On the other 
hand, high instability and fluctuations in perceived academic control leads to lower scores in academic classes (Stupinsky, Perry, Hall, \& Guay, 2012).

To this point, research has not yet investigated the link between perceived academic control and major satisfaction. However, it is plausible that perceived academic control is linked to major satisfaction. Prior research found that elevated levels of perceived academic control were associated to academic success and lower levels of anxiety (Graunke \& Woosley, 2005; Perry et al., 2001; Respondek et al., 2017). Additionally, students with elevated levels of perceived academic control self-reported decreased intentions of discontinuing their studies by withdrawing from the university (Respondek et al., 2017). These links to perceived academic control suggest that perceived academic control would also likely correspond to major satisfaction.

\section{Control-Value Theory on Academic Emotions}

Another factor that may affect a variety of academic outcomes is emotions. An emotion is a "complex state of feeling that results in physical and psychological changes that influence thought and behavior" (Cherry, 2018). Building from the definition of achievement emotions, academic emotions in an academic setting can be defined as "emotions tied directly to achievement activities or achievement outcomes" (Pekrun et al., 2007, p. 15). These achievement activities can include studying, taking an exam, listening in class, completing a group project, or completing an internship (Artino, Holmboe, \& Durning, 2012). As discussed above on how perceived academic control is related to students' perceived capability to influence academic outcomes, emotional experiences can be provoked from these academic situations which similarly can impact education setting and influence learning habits, 
engagement of students in class outside work, academic performance, and personal growth (Pekrun, Goetz, Titz, \& Perry, 2002).

Achievement emotions can be organized with respect to three dimensions: object focus, valence, and activation. First, object focus refers to whether the emotions experienced pertain to an activity or the outcome of an activity (Pekrun et al., 2007). For example, outcome-related achievement emotions are experienced in response to academic successes and failures (i.e., pride of passing a difficult exam), while activity-related emotions are connected to the actual activity (i.e., excitement about learning a specific topic or boredom during a lecture; Pekrun et al., 2007). Second, achievement emotions can be classified by their valence as being positive and pleasant or being negative and unpleasant. Third, achievement emotions can be grouped by their degree of activation as being an activating or deactivating emotion (Pekrun et al., 2007). In the control-value theory, these three dimensions of valence, activation, and object focus produce a three-dimensional taxonomy of achievement emotions; academic emotions can be classified as pertaining to the activity or the outcome of an activity, concerned with either positive (joy, pride) or negative (boredom, anxiety) feelings, and activating learning (joy, pride) or deactivating learning (shame, relief; Artino et al., 2012, Pekrun et al., 2007). For example, boredom produced during a lecture can be considered negative, deactivating, and activity-related in the three-dimensional taxonomy of achievement emotions (Artino et al., 2012).

Academic Emotions related to Perceived Control. When achievement emotions are discussed in terms of academic settings only, they are referred to as academic emotions. The control-value theory of achievement emotions looks at the antecedents and effects of emotions produced in academic situations that are related to cognitive appraisal of control and value 
(Pekrun et al., 2002). Control appraisals refer to how an individual perceives the controllability of achievement activities and the outcomes of those activities (Artino et al., 2012). For example, these control appraisals are often related to levels of self-efficacy and the understanding of one's own ability. Value appraisals refers to the subjective importance some individuals place on achievement activities and outcomes (Artino et al., 2012). Pekrun (2006) identified the negative emotion of boredom as being a perception that achievement-related activities lack value. Similarly, just as attributions can be either internal or external, value appraisals can be either intrinsic or extrinsic. An intrinsic value is the subjective enjoyment that an individual received from completing a certain task, such as inherent interest and enjoyment in a psychology course (Artino et al., 2012). An extrinsic value is completing an activity due to the belief that the activity will lead to an external reward, such as placing value on an academic class because it will lead to graduating with a degree (Artino et al., 2012). The control-value theory proposes that the relationship between cognitive appraisals and emotions is bidirectional (Artino et al., 2012). For example, the emotion of enjoyment that is produced from completing a history paper can influence the intrinsic value appraisal. On the other hand, the emotion of test anxiety that is produced during a testing situation can influence an individual's sense of self-efficacy (control appraisal; Artino et al., 2012, Pekrun et al., 2002).

Academic Emotions in Academic Outcomes. The control-value theory explains how achievement emotions can "influence cognitive resources, motivation, use of strategies, and self-regulation vs. external regulation of learning (Pekrun et al., 2007, p. 16). Emotions experienced in academic settings vary in frequency and intensity depending on the individual and the environment (Pekrun et al., 2002). Emotions can also influence student achievement and personal development (Pekrun et al., 2002). In general, positive emotions are associated 
with beneficial academic outcomes, such as elevated levels of academic performance, motivation, and cognitive performance (Ahmed, van der Werf, Kuyper, \& Minnaert, 2013; Pekrun et al., 2002). On the other hand, negative emotions are connected with negative academic outcomes, such as decreased academic performance and motivation (Ahmed et al., 2013; Pekrun et al., 2002).

The activation dimension of achievement emotions can aid in understanding how positive and negative emotions influence outcomes. For example, ambivalence can result from the deactivation of the positive emotion of relaxation, which can have a lasting impact on future academic outcomes (Artino et al., 2012; Pekrun, 2006). Aspinwall (1998) concluded that positive emotions were more than just feeling good; by maintaining the emotions that "feel good", individuals can often ignore unpleasant emotions and become oblivious to information that would have otherwise been useful. On the other hand, negative emotions can provide useful information, such as helping to propel an individual towards better preparing for a medical exam (Artino et al., 2012; Pekrun, 2006).

Research has further investigated how positive and negative emotions play a role in students' academic activities and outcomes. Goetz, Frenzel, Stoeger, and Hall (2010) found that the positive emotions of joy, being proud, and being content lead to placing higher value on the activity. Pekrun et al. (2002) found that joy, hope, and pride lead to increased levels of academic performance. While the emotion of boredom is less disruptive in educational settings compared to anger and anxiety, boredom in academic settings has been receiving more research attention (Pekrun et al., 2010). Perry et al. (2001) concluded that higher levels of effort, and lower levels of boredom and anxiety were linked to increased motivation in academia and lead to higher final grade scores. The negative emotion of boredom was also 
found to be related to reduced subjective value in achievement settings that lead to attention problems, and negatively impacted motivational engagement and performance; and boredom was also found to be related to overall dissatisfaction with life and an increased chance of depression (Farmer \& Sundberg, 1986; Pekrun, Goetz, Daniels, Stupniksy, \& Perry, 2010). Finally, boredom was found to decrease as students' grade level in college progressed, which could indicate that students with higher levels of boredom withdraw from the university or change their area of study to something that is intriguing and challenging (Dawood, Ghadeer, Mitsu, Almutary, \& Alenezi, 2016). Among first- and second-year students attending a STEMoriented university, Respondek et al. (2017) found that the academic emotion of anxiety mediated the effects of perceived academic control on students' drop-out intentions, but they did not find evidence for an association between academic emotions and academic success.

To this point, research has not investigated the link between academic emotions and major satisfaction. However, it is plausible that academic emotions are linked to major satisfaction. Pekrun et al. (2002) found that joy, hope, and pride lead to higher levels of academic performance. Research found that boredom was related to overall dissatisfaction with life and reduced subjective value in achievement settings that lead to attention problems, and negatively impacted motivational engagement and performance (Farmer \& Sundberg, 1986; Pekrun, Goetz, Daniels, Stupniksy, \& Perry, 2010). These links between academic emotions and academic outcomes likely demonstrate that academic emotions will correspond to major satisfaction. The emotions of joy, hope, and pride would potentially relate to major satisfaction. On the other hand, the emotions of boredom, anxiety, and hopelessness would presumably connect to major dissatisfaction. 


\section{Action Control Theory}

Among social psychologists, there is a general consensus that human behavior is goaldirected (Menec, 1995). Prior theories focused on the relationship between choice and action. However, these prior theories failed to take into account that additional processes may interfere and therefore inhibit the completion of a behavior that was established to obtain a certain goal (Kuhl, 1994; Mene, 1995). Julius Kuhl (1994) developed action control theory to address how individuals presented with external distractions or competing action alternatives continue their intended action; this theory also looks at action orientation versus state orientation as the gap between choice and action. What enables individuals to protect an intention from external distractions and action alternatives are referred to as volition, self-regulation, or action control (Ajzen, 1985; Menec, 1995).

The action control theory outlines that selection of a goal, persistence, and flexibility are fundamental premises that drive and accomplish human goals and behaviors (Ajzen, 1985; Kuhl \& Goschke, 1994; Menec, 1995). First, individuals commonly generate a variety of goals or ideas that align with their values; these ideas will be further narrowed down until a single goal is selected to be fulfilled (Menec, 1995). Second, because external distractions or competing action alternatives can interfere with the completion of the goal, an individual applies persistence to proceed in fulfillment of the goal (Menec, 1995). Third, circumstances can change which will influence a course of action. When situations shift, individuals need to be flexible to alter their behaviors depending on their situation to accomplish their goal (Menec, 1995).

As stated in the action control theory, volitional mechanisms enable an individual to be protective of his or her selected goal by being persistent and flexible to external distractions or 
competing action alternatives (Kuhl \& Goschke, 1994; Menec, 1995). When deciding on a particular goal to act upon, motivation is another factor that aids an individual in this process of withstanding external distractions or competing action alternatives (Kuhl \& Goschke, 1994; Menec, 1995). For example, when a student establishes the goal of approaching his or her professor for guidance on a major term paper before the deadline, motivation can help the student establish and fulfill this goal. Before approaching the professor for guidance, volitional control strategies may need to be invoked when the student is confronted with the alternative of going out to eat with friends instead of asking the professor for guidance. According to the action control theory, volitional processes can be engaged when a conflict arises between what an individual intends to do and what an individual wants to do (Ajzen, 1985; Kuhl \& Goschke, 1994; Menec, 1995). The use of persistence and motivation can help the student fulfill his or her goal of achieving a better grade in a course by talking to the professor about their term paper instead of abandoning this goal and going out to eat with friends. These volitional mechanisms can help students protect their academic goals to be successful in their academic outcomes.

When an individual encounters challenges or obstacles, action control strategies are invoked to protect the execution of an intention (Kuhl, 1994). Volitional mechanisms are engaged only when conflict arises between the three separate mental subsystems (levels of control): cognitive, emotional/motivational, and executional processing (Ajzen, 1985; Kuhl \& Goschke, 1994). Cognitive preferences relate to intentions; an intention can be defined as a representation of an action plan that an individual intends to execute (Kuhl \& Goschke, 1994; Menec, 1995). Emotional preferences refer to the emotions that are elicited or experienced from a past activity (Kuhl \& Goschke, 1994; Menec, 1995). These emotions that are elicited 
are used in the process to emotionally evaluate a specific action (Kuhl \& Goschke, 1994; Menec, 1995). Executional preferences refer to the strength of the behavioral responses that represent the established plan of action or intention (Kuhl \& Goschke, 1994; Menec, 1995). Kuhl (1985) defined six volitional strategies that can be used when conflict arises between the three mental subsystems, as mentioned above, to help maintain the goal of acting upon the established intention (Kuhl \& Goschke, 1994; Menec, 1995; Menec \& Schonwetter, 1994). These strategies include 1) selective control of attention, which refers to placing focus exclusively on information that is related to the intention; 2) encoding control, which involves selective encoding of information that is related to the intention; 3) economy of information processing, which involves optimizing the amount of time spent on processing the intention and inhibiting the amount of time considering action alternatives or external distractions; 4) control of emotions, which refers to reducing emotions that may interfere with an intention, and eliciting emotions that promote an established intention; 5) motivational control, which refers to reinforcing the motivation that originally established the intention; 6) environmental control, which refers to creating an environment that will help enable an individual to execute their intention (Kuhl \& Goschke, 1994; Menec, 1995). Individuals can employ these volitional strategies to protect and act upon an intention.

Preoccupation with Failure. The action control theory states that the two models of state orientation and action orientation, which are generally considered to be on two opposite ends of a spectrum, influence an individual's ability to invoke volitional control strategies to protect and act upon their intentions (Kuhl \& Goschke, 1994; Menec, 1995). Action orientation refers to the "efficient functioning of volitional processes" (Menec, 1995, p.11). On the other hand, state orientation refers to the "inability to control cognitions and emotions that are not 
related to a current intention and an inability to initiate a new action when exposed to stressful experiences" (Menec, 1995, p.11). When presented with external distractions and action alternatives, individuals who tend to have state-orientation struggle to apply volitional strategies to protect their intention. Kuhl (1994) describes three types of state orientation: preoccupation, hesitation, and volatility. Preoccupation state-orientation refers to a persistent focus that is often intrusive and uncontrollable on failure that stems from negative, stressful events (Kuhl \& Goschke, 1994; Menec, 1995; Perry et al., 2001). Hesitation state-orientation refers to the inability to act upon an intention (Kuhl \& Goschke, 1994; Menec, 1995). Lastly, volatility state-orientation refers to the inability to continue activities that are pleasant without eventually changing to an alternative activity (Kuhl \& Goschke, 1994; Menec, 1995). Although it is possible that any of the types of state orientation could affect major satisfaction, as is described below, preoccupation with failure seems especially relevant because it deals with monitoring negative feedback which can be a common occurrence in academic settings.

\section{Perceived Academic Control and Preoccupation with Failure}

As stated above, perceived academic control refers to a student's perceived understanding of their influence over their academic outcomes (Perry et al., 2005) and preoccupation with failure refers to the focus on the negative, stressful event of failure (Perry et al., 2001). Perry et al. (2001) introduced research that combined the concepts of perceived academic control and preoccupation with failure to better understand the successes and failures of college students. Perry et al. (2001) investigated how students' beliefs about their academic control (perceived academic control) and examination of failure (preoccupation with failure) influenced academic performance and outcomes. Prior research on preoccupation with failure produced divergent results depending on the academic context that was being researched 
(Perry et al., 2001), so Perry et al. wanted to further understand if preoccupation with failure could be a factor to why some students who are intelligent and enthusiastic do not successfully complete college (Perry et al., 2001). The study revealed that students who had increased levels of academic control and high preoccupation with failure had better academic performance (Perry et al., 2001). Thus, although preoccupation with failure might seem to be to a student's detriment on the surface, being preoccupied with failure might have a positive influence on academic performance in some cases. Students with a strong tendency to be preoccupied with failure and who have moderate to high perceived academic control are likely to have heightened focus on past academic failures, which relates to the process of seeking to identify and better understand the causes of their failures. Seeking to understand the cause of failures is similar to Weiner's $(1982,2010)$ idea of causal search (Perry et al., 2001). Efforts toward achievement can be increased when students who have high perceived academic control understand their failures as controllable causes. According to the attribution theory in combination with the concept of preoccupation with failure, students who view themselves as having control over their academic outcomes should increase efforts toward academic success following a failure (Perry et al., 2001; Weiner, 2010). Because those students would perceive some control over academic successes and failures, it seems likely that they would experience academic emotions such as hope, as opposed to emotions such as anger and hopelessness, which should protect against low academic major satisfaction. Thus, an interaction between perceived academic control and preoccupation with failure might be expected.

\section{Possible Developmental Shifts in Predictors of Academic Major Satisfaction}

When students enter higher education, there is a shift in responsibilities that elicit them to become more accountable for their academic success and enjoyment (Appleby, 2006). Perry 
et al. (2001) found that students' first academic year was critical to their overall success during college. A successful transition to higher education includes students adapting to their new academic environment, gaining an understanding of the resources the institution provides to help their students be successful, and a comprehension of the skills and attitude required to take responsibility for their academic success and journey (Appleby, 2006). Appleby (2006) identified several differences that students experience from the transition to higher education. These differences include the generalizations that college knowledge is self-taught, professors expect more from their students, and more time is required to be spent studying in order to learn more material that is academically challenging (Appleby, 2006). During this transition period to higher education, students devote increased efforts in selecting a college major, learning how to manage the new responsibilities of being in college, interpret their successes and failures, and understanding how to balance their social life with academics.

The concepts of perceived academic control and preoccupation with failure appear to serve a greater purpose in academic success when students are in their first couple years of entering college. As students gain more experience and near the end of their college career, their focus is likely to turn towards finding a job, moving to a new city, and networking with other professionals in their field. These new situations faced during the last years of college pull students attention away from preoccupation with failure and perceived control related to academics which once served useful in helping them pursue their college major and be successful in academics. Additionally, these new demands and environments along with academic pressure can lead students to experience various emotions. During this critical adjustment period, Perry (1991) found that students had improved capabilities of managing the situation with the thought process that they had control over their outcomes. 
The aforementioned possible predictors of major satisfaction — perceived academic control, academic emotions, and preoccupation with failure — may vary in importance depending on a student's year in school. Research investigating student satisfaction and retention rates found that global satisfaction scales were predictive of freshmen retention rates, but satisfaction became less of a predictor at each consecutive grade level (Schreiner, 2009). It seems likely — though not yet empirically verified--that students' satisfaction with their majors will increase as their studies progress. This is largely because students will leave unsatisfying majors in favor of those that they expect to be more satisfying (Holland, 1997). When students enter higher education, they have not been exposed to the wide variety of career fields or maybe do not have a concrete idea of what they want to pursue in their future. As students gain a better understanding of themselves during college, they are likely to select a major that matches their interests and values or change their major to better fit their interests, which will lead to increased major satisfaction. Additionally, students who are not satisfied with their college major and have low levels of perceived academic control may withdraw from the university altogether. Given that the predictors of major satisfaction should lead to shifts to more satisfying majors over time, it is expected that the predictors will be more strongly associated with major satisfaction early in students' academic careers.

\section{Purpose of this Study and Hypotheses}

The purpose of this study was to explore how preoccupation with failure, perceived academic control, and academic emotions are associated with students' major satisfaction. While many factors have been linked to major satisfaction, many of them—such as institutional characteristics and students' interests and abilities--cannot be addressed by counselors. In contrast, understanding the role that preoccupation with failure, academic 
emotions, and perceived academic control play in major satisfaction can assist counselors and teachers with intervention by revealing whether it is likely to be effective to modify students' thinking about their experiences in their major area of study.

Hypothesis 1: It was hypothesized that higher perceived academic control would be positively related to major satisfaction. Prior research found that higher levels of perceived academic control were related to academic success, lower levels of anxiety, increased effort in academia, and elevated levels of motivation (Graunke \& Woosley, 2005; Perry et al., 2001; Respondek et al., 2017). However, prior research has not investigated the effects of students' perceived academic control of academic successes and failures in relation to the outcome measure of this study, major satisfaction. With research demonstrating that perceived academic control corresponds to academic success and drop-out intentions, it seemed likely that academic success would also be linked to perceived academic control (Respondek et al., 2017).

Hypothesis 2: It was hypothesized that positive academic emotions will be associated with increased levels of major satisfaction, while the negative emotions will be negatively associated with major satisfaction. Pekrun et al. (2002) found that joy, hope, and pride lead to higher levels of academic performance. There has not been research on how academic emotions are related to major satisfaction. From prior research that found a connection between the emotions of enjoyment, hope, and pride on academic performance, it was deemed likely that these emotions would have similar associations with major satisfaction.

Hypothesis 3: It was hypothesized that preoccupation with failure would have a curvilinear relationship with major satisfaction. Perry et al. (2001) found that preoccupation with failure was positively associated with academic performance and academic outcomes. Although Perry et al. did not examine major satisfaction as an outcome, a similar association 
would be expected given Perry et al.'s speculation that moderate preoccupation with failure may motivate students to work hard on academic tasks. However, preoccupation with failure in the extreme could be paralyzing and lead to inaction, so this relation was not expected to be linear.

Hypothesis 4: It was hypothesized that preoccupation with failure would moderate the effect of perceived control on major satisfaction. Perry et al. (2001) found that increased levels of preoccupation with failure and academic control led to improved academic performance. It is possible that heightened levels of perceived academic control cannot entirely account for a student's academic success. Students who have higher levels of perceived academic control but low preoccupation with failure may simply not have the motivation to focus on their failures and plan to pursue their academic goals. Thus, the association of perceived control with major satisfaction was expected to be weakest at low levels of preoccupation with failure.

Hypothesis 5: It was hypothesized that the academic emotion of anxiety has a mediating role between perceived academic control and major satisfaction. Respondek et al. (2017) discovered that there was not a direct relationship between perceived academic control and dropout intention, but rather the emotion of anxiety produced a full mediating effect. A similar pattern was expected with major satisfaction as the outcome variable.

Hypothesis 6: It was hypothesized that year in school moderates the effect of preoccupation with failure, perceived academic control, and academic emotions on major satisfaction. As students near graduation, their attention turns toward future tasks such as finding a job, moving to a new city, and networking with other professionals in their field. Their future focus may reduce the degree to which major satisfaction is determined by 
academic control, emotions and preoccupation with failure; instead they may base their major satisfaction on their sense of whether their major is leading to good career options. 


\section{CHAPTER III: METHOD}

\section{Participants}

The sample consisted of college students who were recruited from a large, Midwestern, Public university's psychology department participant pool. A total of 462 participants accessed the survey and clicked "yes" for consent. Of this group, 16 cases were discarded because no survey items were completed, and 60 additional participants were excluded who did not meet the demographic inclusion criteria (i.e., graduate students) or who failed one or both attention check items (i.e. Please select "Strongly Disagree”) that were dispersed throughout the survey. This resulted in a sample 386 cases that were used for analyses.

Participants self-identified their gender as female $(n=332,86 \%)$ and male $(n=54$, $14 \%)$. The participants indicated being between the ages of 18 to $46(M=19.49, S D=2.22)$. Participants self-identified their race/ethnicity as Hispanic or Latino $(n=45,11.7 \%)$, African American or Black $(n=32,8.3 \%)$, Asian or Pacific Islander $(n=9,2.3 \%)$, White or Caucasian $(n=293,75.9 \%)$, or other $(n=7,1.8 \%)$. In terms of class rank, participants identified as freshman $(n=185,47.9 \%)$, sophomore $(n=70,18.1 \%)$, junior $(n=75,19.4 \%)$, and senior $(n$ $=56,14.5 \%)$. In terms of changing majors, participants reported changing their major 0-1 times $(n=343,88.9 \%), 2-3$ times $(n=40,10.4 \%)$, and $4-5$ times $(n=3, .8 \%)$. Participants reported studying an average of 13.52 hours per week $(S D=9.86)$, and participants reported an average likeliness to withdraw from the university prior to earning a degree score of $1.83(S D=$ 3.01) on an 11-point Likert scale that ranged from zero (not at all likely) and 10 (extremely likely). Participants had a wide variety of majors, with the most common being psychology, nursing, education, exercise science, criminal justice, and communications. 


\section{Measures}

Academic Control. Perceived academic control was measured with an 8-item selfreport measure developed by Perry et al. (2001). The items are rated on a 5-point Likert scale that ranges from one (strongly disagree) to five (strongly agree). Participants were prompted to respond to the eight items regarding their current classes in their selected major. A possible range of scores was 8 to 40, where higher scores indicate more perceived academic control and the lower scores signify less perceived academic control over their outcomes. Sample questions include, "No matter what I do, I can't seem to do well in my courses," and "When I do poorly in a course, it's usually because I haven't given my best effort.” Perry et al. (2007) reported that the Cronbach's alpha coefficient was .80 for the eight items. The internal consistency estimate for the present study was $\alpha=.84$. In previous research, the academic control measure's test-retest reliability was .59 at five months (Perry et al., 2005). Perceived control has been linked to enhanced adjustment after stressful events, overall academic success, and enhanced motivation (Frazier et al., 2011; Perry et al., 2001; Skinner, 1996). Prior research found that perceived academic control was positively related to enjoyment, motivation, academic success, and achievement and negatively related to anxiety, boredom, and dropout intention (Perry et al., 2001; Perry et al., 2005; Respondek et al., 2017).

Positive and Negative Emotions. To measure emotions toward classes in their chosen majors, participants completed the Positive and Negative Affect Schedule (PANAS; Watson, Clark, \& Tellegen, 1988). The PANAS consists of two mood scales that capture positive affect and negative affect. The measure consists of 20 self-report items to which participants respond using a 5-point Likert scale that ranges from one (very slightly or not at all) to five (extremely). The positive affect scale includes enthusiastic, interested, determined, excited, inspired, alert, 
active, strong, proud, and attentive whereas the negative affect scale includes scared, afraid, upset, distressed, jittery, nervous, ashamed, guilty, irritable, and hostile (Watson et al., 1988). Participants were asked to indicate the extent to which they felt each emotion over the past week regarding the classes in their chosen major. To calculate a total score, the scores from the ten positive affect items are summed and the scores from the ten negative affect items are summed. The possible range of target scores for positive and negative affect is 10 to 50 , where higher scores indicate greater identification with either positive or negative affects. Watson et al. (1988) reported that the Cronbach's alpha was .86 to .90 for the positive affect scale and .84 to .87 for the negative affect scale. The estimated internal consistency for the present study was $\alpha=.94$ and .90 for the positive affect and negative affect scales, respectively. In previous research the test-retest reliability was .81 and .79 at one week for the negative affect and positive affect scales, respectively (Watson et al., 1988). In support of the PANAS scale scores' validity, Watson et al. (1988) correlated the negative affect scale to the Hopkins Symptoms Checklist, the Beck Depression Inventory, and the State-Trait Anxiety Inventory State Anxiety Scale.

Academic Emotions (Boredom and Anxiety). Two specific emotions, boredom and anxiety, were of particular interest in this study, so an additional measure of emotions was included to assess these two emotions more reliably. The Achievement Emotions Questionnaire (AEG; Pekrun et al., 2005) measures class-related emotions. The original measure consists of three sections that assess class-related, learning-related, and test-related emotions. Although it would have been ideal to have participants complete all three sections, the time required to do so would have been prohibitive; therefore, participants only completed the section dealing with class-related emotions of anxiety and boredom because this section 
seems most likely to be linked with major-specific satisfaction (as opposed to general academic performance). The class-related emotion items are rated on a 5-point Likert scale that ranges from one (strongly disagree) to five (strongly agree). Although the original items ask participants to answer based on their feelings about a particular class, the wording in the current study was modified so that students were asked about "classes in my major."

Anxiety. This subscale includes 12 items with a possible range of scores from 12 to 60 , where higher scores indicated more anxiety in class-related activities. A sample question includes, "Thinking about class makes me feel uneasy" and "I get tense in class."

Boredom. This subscale includes 11 items with a possible range of scores from 11 to 55, where higher scores indicated more boredom in class-related activities. Sample questions include, "Because I get bored my mind begins to wander," and "I am tempted to walk out of the lecture because it is so boring."

The AEQ was developed in the German language; a group of experts used a backtranslation procedure to convert the scale into the English language (Pekrun et al., 2005). Pekrun et al. (2005) reported that the reliability of the AEQ scales range from adequate to very good, with a Cronbach's alpha of .75 to .93 . Additionally, 20 of the 24 scales had a Cronbach's alpha above .80 . The estimated internal consistency for the present study was $\alpha=.92$ and .95 for the emotions of boredom and anxiety, respectively. The majority of the correlations between the eight emotion scales of the AEQ are only low to medium in strength. These correlations indicate discriminant validity amongst the eight emotion scales (Pekrun et al., 2005). Respondek et al. (2017) found that perceived academic control was positively related to the emotion of enjoyment, and negatively related to the emotions of anxiety and boredom. When looking at perceived academic control and the academic emotion of anxiety, Respondek 
et al. (2017) found that students who had lower levels of perceived academic control and elevated anxiety, had increased dropout intentions.

Preoccupation with Failure. The action control theory developed by Kuhl (1994) introduced a 12-item, forced-choice questionnaire to measure preoccupation with failure. The original Action Control Scale assessed the three subscales of preoccupation-related, hesitationrelated, and volatility-related state orientation. However, the participants in the current study completed only the action control questionnaire with suggested adjustments from Perry et al. (2001) to have a greater focus on academic outcomes. The 12 items require participants to report which of two alternatives they agree with. The possible range of scores is 12 to 24 , where lower scores signify an intense focus on past, present, and future outcomes that are associated with failure and rumination (i.e., state-oriented) and higher scores indicate less focus on past, present, and future outcomes of failure and rumination (i.e., action-oriented; Perry et al., 2001). Examples of items include "If I have to talk to someone about something important and, repeatedly, can't find her or him at home: (a) I can't stop thinking about it, even while I'm doing something else, (b) I easily forget about it until I can see the person again," and "If I'm stuck in traffic and miss an important appointment: (a) At first, it's difficult for me to start doing anything else at all, (b) I quickly forget about it and do something else." Previous research has found Kuder-Richardson 20 reliability coefficients to range from .71 to .79 (Brunborg et al., 2010; Hamm et al., 2014; Perry et al., 2001). The Kuder-Richardson 20 reliability coefficient in the present study was .70. Depending upon the academic context, prior research on preoccupation with failure produced divergent results (Perry et al., 2001). However, higher levels of preoccupation with failure were positively related to academic success (Perry et al., 2001). 
Major Satisfaction. To measure academic major satisfaction, participants completed the Academic Major Satisfaction Scale (AMSS; Nauta, 2007). The measure is designed to assess college students' global satisfaction based on their choice of college major. The AMSS consists of six unidimensional self-report items on a 5-point Likert scale that range from one (strongly disagree) to five (strongly agree). To calculate a total score, the scores from the six item responses were averaged. The possible range of scores was 1 to 6 , where higher scores indicate greater major satisfaction. Sample questions include "I wish I was happier with my choice of an academic major (reverse scored)," and "I feel good about the major I've selected." Nauta (2007) reported that the Cronbach's alpha was .90 for the six item. The estimated internal consistency for the present study was $\alpha=.92$. The AMSS has been shown to be positively correlated with students' GPAs and career decision self-efficacy and negatively associated with career-choice anxiety and generalized indecisiveness (Nauta, 2007). AMSS scores are predictive of changing majors over a 2-year period (Nauta, 2007).

Demographic, Control, and Validation Items. In order to describe the sample, participants were asked to respond to a number of demographic items. Additionally, some questions were included to assess factors already known to be associated with major satisfaction (i.e., interest congruence) or likely to be associated with major satisfaction (e.g., study hours) so that those could be controlled for in the analyses.

Demographic items. Participants identified their gender, age, race/ethnicity, college major, and year in school using forced-choice and open-ended responses. Because it might help with interpreting the findings, students were also asked to self-report the number of hours they spend on study activities each week. Study activities listed in the instructions for the item included self-study, lectures, tutorial, private seminars, and group study sessions. Students 
were also asked to report the number of semesters they had spent in their current majors and how many times the participant had changed majors.

Control item. Students completed a single-item pictorial measure that assessed the degree to which their interests overlap with their chosen major. The interest overlap question was based off the Inclusion of Other in the Self (IOS) Scale that was developed by Aron, Aron, and Smollan (1992). The interest overlap question contained seven Venn-like diagrams that represented different degrees of overlap between two circles, "My Interests" and "My Major". The total area of the circles in each image was constant, so the degree of overlap between the circles increased linearly and produced seven interval-level images. Participants selected the image that best represented the relationship between their interests and chosen major.

Validity items. Previous research (Nauta, 2007) revealed major satisfaction to be associated with college performance, and it has been hypothesized that major satisfaction might be a reasonable early indicator of students' drop-out intentions (Nauta, 2007). To examine whether this pattern of findings would be supported with the current sample, students were asked to self-report their grade point average using forced-choice responses that ranged from 1.19 to 4.00 . They indicated their drop-out intentions from the university using a response scale that ranged from 1 (not at all likely) to 10 (extremely likely).

\section{Procedure}

Before the commencement of data collection, the Institutional Review Board (IRB) at Illinois State University reviewed and approved the study. Students were recruited through enrollment in psychology classes with access to the survey via an online sign-up system. The first page of the survey consisted of a consent screen which outlined the terms to be accepted before participation in the survey. After the consent screen, participants completed the 
measures described above, which were administered in a counterbalanced order. The final screen of the survey contained debriefing information and provided students with information about how to access their university's career and counseling services. 


\section{CHAPTER IV: RESULTS}

To investigate if missing data values were missing at random, a Little's Missing Completely at Random (MCAR) test was completed. The Little's MCAR value was nonsignificant, $\chi^{2}(31)=33.283, p=.36$; this suggests that the pattern of missing values does not depend on the data values and it was deemed safe to use listwise deletion to deal with missing data for the analyses.

Means, standard deviations, and bivariate correlations were calculated for all of the measures and are shown in Table 1. 
Table 1

Means, Standard Deviations, and Correlations among the Measures

$\begin{array}{lllllllllllll}\text { Measure } & 1 & 2 & 3 & 4 & 5 & 6 & 7 & 8 & 9 & 10 & 11 & 12\end{array}$

1. Positive PANAS

2. Negative PANAS $\quad-.28^{* *}$

3. AE Anxiety - $-.32 * * \quad .62 * *$

w

4. AE Boredom $\quad-.43 * * \quad .37 * * \quad .44 * *$

5. Academic Control $\quad .29 * * \quad-.33 * * \quad-.47 * * \quad-.31 * *$

$\begin{array}{llllll}\text { 6. Preoc. with Failure } \quad .23 * * & -.27 * * & -.40 * * & -.19 * * & .17 * *\end{array}$

7. Major Satisfaction $\quad .52 * * \quad-.38^{* *} \quad-.30 * * \quad-.37 * * \quad .31 * * \quad .16 * *$

$\begin{array}{lllllllll}\text { 8. Year in School } & .02 & .07 & -.06 & -.07 & .05 & .11^{*} & .08\end{array}$

$\begin{array}{llllllllll}\text { 9. Study Hours } & .11 * & .02 & .00 & -.09 & .07 & -.01 & .07 & -.08\end{array}$ 


\begin{tabular}{|c|c|c|c|c|c|c|c|c|c|c|c|c|}
\hline Measure & 1 & 2 & 3 & 4 & 5 & 6 & 7 & 8 & 9 & 10 & 11 & 12 \\
\hline 10. GPA & $.21 * *$ & $-.28 * *$ & $-.30 * *$ & $-.21 * *$ & $.45^{* *}$ & -.04 & $.30 * *$ & -.02 & .06 & & & \\
\hline 11. Interests Overlap & $.36^{* *}$ & $-.15 * *$ & $-.16 * *$ & $-.25 * *$ & $.16^{* *}$ & .07 & $.44 * *$ & .05 & $.10 *$ & $.17 * *$ & & \\
\hline $\bar{M}$ & 34.17 & 19.73 & 27.10 & 28.47 & 33.18 & 16.57 & 25.84 & 2.01 & 13.52 & 2.56 & 4.96 & 1.83 \\
\hline$S D$ & 9.19 & 7.88 & 10.85 & 10.71 & 5.24 & 2.73 & 5.51 & 1.12 & 9.86 & 1.42 & 1.55 & 3.01 \\
\hline
\end{tabular}

Note. $\mathrm{AE}=$ academic emotion;

$* p<.05, * * p<.01$. 
Hypothesis 1, which stated that higher perceived academic control would be positively related to major satisfaction was tested by examining the correlation between scores on the AMSS and the perceived academic control measure. The correlation was significant, $r(384)=$ $.31, p=.00$. Thus, hypothesis 1 was supported, indicating that those with higher levels of perceived control over their academics reported increased satisfaction in their major.

Hypothesis 2, which stated that academic emotions would be associated with major satisfaction was tested by examining the correlations between the scores on the PANAS and AMSS. The correlation of the positive affect scale and AMSS scores was significant, $r(384)=$ $.52, p=.00$. Similarly, the correlation of the negative affect scale and the AMSS scores was significant, $r(384)=-.38, p=.00$. Both were in the expected directions. Anxiety and boredom were of particular interest in this study, and these specific negative emotions were also shown to be negatively correlated with major satisfaction, $r(384)=-.30, p<.01$, and $r(384)=-$ $.37, p<.01$, respectively. Thus, hypothesis 2 was supported.

To test hypothesis 3 , which stated that preoccupation with failure would have a curvilinear relationship with major satisfaction, a hierarchical regression analysis was conducted. Major satisfaction was the criterion variable in the analysis. Preoccupation with failure was entered as a predictor in one step, and squared preoccupation with failure values were entered as a second step. The analysis (see Table 2) revealed that preoccupation with failure explained a significant proportion of variance in major satisfaction, $R^{2}=.03, F(1,383)$ $=9.62, p=.002$. In multiple regression the effect size is indicated by the value of $R^{2} . R^{2}$ values between .010 and .058 are considered to represent a small effect, those between .059 and .137 are considered to represent a medium effect, and those .138 or higher are considered to represent a larger effect (Cohen, 1988), so preoccupation with failure had a small effect. 
Contrary to expectation, the squared preoccupation with failure term in the second step did not increase the proportion of variance explained, $\Delta R^{2}=.000, F(1,382)=0.11, p=.74$. The predictors still explained $3 \%$ of the variance in major satisfaction, $F(2,382)=4.86, p=.008$. Therefore, the data did not support the idea that preoccupation with failure would have a curvilinear relationship with major satisfaction.

Table 2

Results of Hierarchical Linear Regression Analysis Testing Predicted Curvilinear Relationship between Preoccupation with Failure and Major Satisfaction

\begin{tabular}{lcccc}
\hline \multicolumn{1}{c}{ Predictor } & $R^{2}$ & $B$ & $S E B$ & $\beta$ \\
\hline $\begin{array}{l}\text { Model 1 } \\
\quad \text { Preoccupation with Failure }\end{array}$ & $.03^{* *}$ & & & \\
Model 2 & $.03^{* *}$ & .32 & .10 & $.16^{* *}$ \\
$\quad$ Preoccupation with Failure & & .67 & 1.04 & .33 \\
$\quad$ Preoccupation with Failure & & -.01 & .03 & -.17 \\
\hline
\end{tabular}

Note. $\Delta R^{2}$ from Model 1 to Model $2=.00$.

$* p<.05 ; * * p<.01 ; * * * p<.001$.

$N=384$

To test hypothesis 4 , which stated that there would be an interaction between preoccupation with failure and academic control in the prediction of major satisfaction, another hierarchical regression analysis was conducted. Major satisfaction was the criterion variable, but this time academic control, preoccupation with failure, and the interaction term were predictors. The regression analysis (see Table 3) revealed that preoccupation with failure and academic control explained a significant proportion of variance in major satisfaction, $R^{2}=.11$, $F(2,382)=22.85, p<.001$. The effect size indicates that these variables together had a medium effect. Contrary to expectation, the interaction term in the second step did not increase the proportion of variance explained, $\Delta R^{2}=.001, F(1,381)=0.29, p=.59$. The two blocks of variables together still explained $11 \%$ of the variance in major satisfaction, $F(3,381)=15.30$, 
$p<.001$. Therefore, the data did not support the idea that the association between academic control and major satisfaction varies depending on the level of students' preoccupation with failure.

Table 3

Results of Hierarchical Linear Regression Analyses Predicting Major Satisfaction based on Academic Control and Preoccupation with Failure

\begin{tabular}{lcccc}
\hline \multicolumn{1}{c}{ Predictor } & $R^{2}$ & $B$ & $S E B$ & $\beta$ \\
\hline Model 1 & $.11^{* * *}$ & & & \\
Academic Control & & .31 & .05 & $.29^{* * *}$ \\
Preoccupation with Failure & & .22 & .10 & $.11^{*}$ \\
Model 2 & $.11^{* * *}$ & & & \\
Academic Control & & .15 & .30 & .14 \\
Preoccupation with Failure & & -.12 & .64 & -.06 \\
Control X Preoccupation & & .01 & .02 & .25 \\
\hline
\end{tabular}

Note. $\Delta R^{2}$ from Model 1 to Model $2=.001$.

$* p<.05 ; * * p<.01 ; * * * p<.001$.

$N=384$

To test hypothesis 5, which stated that anxiety would be a mediator between academic control and major satisfaction, a path analysis was conducted. The unstandardized coefficients presented in Figure 1 partially supported the theorized model. Perceived academic control was negatively associated with anxiety, and anxiety was negatively associated with major satisfaction. While controlling for anxiety, academic control significantly predicted major satisfaction. Bootstrap analyses with 1,000 samples revealed that the unstandardized indirect effect $(.10 ; 95 \%$ C.I. $=.04, .17)$ was significant. Therefore, hypothesis 5 was partially supported due to anxiety being only a partial mediator. 


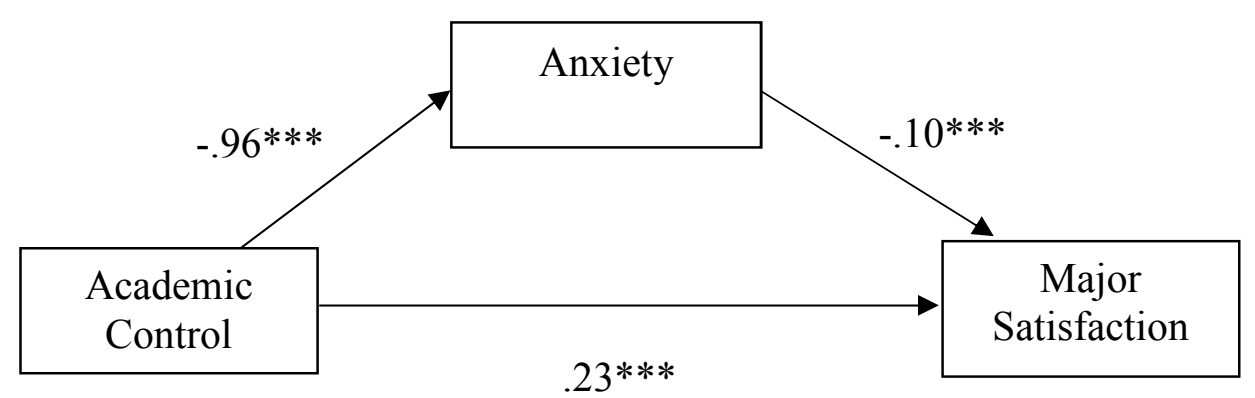

Figure 1. Path Analysis of the Mediating Effect of Anxiety in the Relationship of Academic Control and Major Satisfaction

$* p<.05 ; * * p<.01 ; * * * p<.001$

To test hypothesis 6 , which stated that year in school would moderate the associations of preoccupation with failure, academic control, and academic emotions with major satisfaction, a final hierarchical regression analysis was conducted. Major satisfaction was the criterion, and the predictors were academic control, preoccupation with failure, academic emotions, year in school, and the interaction terms. The measure of interest overlap with students' chosen major was also added to the regression model in order to examine if the other predictors explain variance in major satisfaction after controlling for that well-established predictor of major satisfaction. The analysis (see Table 4) revealed that year in school, preoccupation with failure, academic control, academic emotions, and interest overlap explained a significant proportion of variance in major satisfaction, $R^{2}=.41, F(6,378)=$ $44.42, p<.001$. The effect size, as estimated by the $R^{2}$ value, indicates that these variables together represented a large effect. Consistent with expectation, the block of variables with the interaction terms in the second step increased the proportion of variance explained, $\Delta R^{2}=0.02$, $F(4,374)=3.09, p=.02$. The two blocks of variable together explained $43 \%$ of the variance in major satisfaction, $F(10,374)=28.48, p<.001$. 
The nature of the significant interaction term in the second block was probed by testing the conditional effects of positive emotions at three levels of year in school (one standard deviation below the mean [value 1.00, equivalent to freshman standing], at the mean [value 2.01, equivalent to sophomore standing], and one standard deviation above the mean [value 3.12, equivalent to slightly higher than junior standing]). As shown in Table 5, positive emotions were significantly related to major satisfaction when year in school was one standard deviation below the mean, at the mean, and one standard deviation above the mean $(p<.001)$; however, the relationship was strongest amongst freshmen and decreased in magnitude across years in school. Therefore, the data did partially support hypothesis 6 . Year in school moderated the association between positive emotions and major satisfaction, although it did not appear to be a moderator of the other predictor variables' associations with major satisfaction. 
Table 4

Results of Hierarchical Linear Regression Analyses Predicting Major Satisfaction based on All Study Variables and Interactions with Year in School

\begin{tabular}{|c|c|c|c|c|}
\hline Predictor & $R^{2}$ & $B$ & $S E B$ & $\beta$ \\
\hline Model 1 & $.41 * * *$ & & & \\
\hline Year in School & & .39 & .20 & $.08 *$ \\
\hline Interests Overlap & & .95 & .15 & $.27 * * *$ \\
\hline Academic Control & & .10 & .05 & $.10 *$ \\
\hline Preoccupation with Failure & & -.06 & .09 & -.03 \\
\hline Positive PANAS & & .21 & .03 & $.34 * * *$ \\
\hline Negative PANAS & & -.16 & .03 & $-.23 * * *$ \\
\hline Model 2 & $.43 * * *$ & & & \\
\hline Year in School & & .97 & 2.02 & .20 \\
\hline Interests Overlap & & .97 & .15 & $.27 * * *$ \\
\hline Academic Control & & .01 & .10 & .01 \\
\hline Preoccupation with Failure & & .10 & .17 & .05 \\
\hline Positive PANAS & & .30 & .05 & $.50 * * *$ \\
\hline Negative PANAS & & -.24 & .06 & $-.35 * * *$ \\
\hline Year X Academic Control & & .05 & .04 & .33 \\
\hline Year X Preoccupation & & -.07 & .07 & -.25 \\
\hline Year X Positive PANAS & & -.05 & .02 & $-.42 *$ \\
\hline Year X Negative PANAS & & .04 & .03 & .22 \\
\hline
\end{tabular}

Note. $\Delta R^{2}$ from Model 1 to Model $2=.01$.

$* p<.05 ; * * p<.01 ; * * * p<.001$.

$N=384$

Table 5

Conditional Effects of Year in School on Major Satisfaction

\begin{tabular}{lcccc}
\hline Major Satisfaction & $\beta$ & $p$ & \multicolumn{2}{c}{$95 \%$ CI } \\
\hline $\begin{array}{l}\text { One SD below mean } \\
\text { (Freshmen) }\end{array}$ & .35 & $<.001$ & .29, & .42 \\
$\begin{array}{l}\text { At the mean } \\
\text { (Sophomore) }\end{array}$ & .30 & $<.001$ & .25, & .35 \\
$\begin{array}{l}\text { One SD above mean } \\
\text { (Junior/Senior) }\end{array}$ & .25 & $<.001$ & .17, & .33 \\
$* p \leq .05$ & & & & \\
\hline
\end{tabular}




\section{CHAPTER V: DISCUSSION}

The purpose of this study was to understand the associations that preoccupation with failure, perceived academic control, and academic emotions may have with students' major satisfaction. Previous studies have shown that academic control, academic emotions, preoccupation with failure, and perceived control are related to academic outcomes and performance; however, there are inconsistencies within the literature regarding preoccupation with failure on academic outcomes (Graunke \& Woosley, 2005; Pekrun, 2006; Perry et al., 2001; Perry et al., 2005; Respondek et al., 2017; Thompson, 2002). While previous research investigated the outcome measures of academic performance and outcomes, one goal of this study was to understand the relationship between preoccupation with failure, perceived academic control, and academic emotions on the outcome measure of major satisfaction. Understanding the relationship of these variables on major satisfaction is important because major satisfaction has been shown to be related to academic performance and career decision self-efficacy, while inversely associated with career-choice anxiety and generalized indecisiveness (Nauta, 2007). The hope was that understanding the role that preoccupation with failure, academic emotions, and perceived academic control play in major satisfaction might assist counselors and professors with identifying possible intervention strategies to increase major satisfaction and aid students in continuing their plan of study. Because major satisfaction can be assessed earlier in a student's academic career than can performance or actual drop-out, it is a useful outcome variable to consider as a means of identifying students who are at risk for leaving college prior to graduating.

The results from the first hypothesis, which stated that perceived academic control would be positively related to major satisfaction, indicate that perceived control over 
academics may play an important role in students' satisfaction with their major. Previous findings had shown that perceived academic control was related to academic success, lower levels of anxiety, and elevated motivation (Graunke \& Woosley, 2005; Perry et al., 2001; Respondek et al., 2017), so the findings of the current study extend the literature by showing that academic control also relates to major satisfaction. Thus, this finding further supports the attribution theory. Importantly, this association between academic control and major satisfaction held even after controlling for the well-established variable of interest overlap between the student and major. As a result, perceived academic control appears to hold promise as an intervention point for increasing students' satisfaction with their majors.

The second hypothesis was also supported, as the positive emotions measured on the PANAS revealed a positive correlation with major satisfaction, and the negative emotions measured on the PANAS showed a negative correlation with major satisfaction. Thus, the control-value theory on academic emotions was supported. Previous literature had shown that the positive emotions of joy, hope, and pride led to increased academic performance (Pekrun et al., 2002), but the current study is the first to examine the role of academic emotions in students' major satisfaction. As with perceived academic control, the positive and negative emotions remained significant predictors of major satisfaction after controlling for the degree to which students' interests overlap with the content of their major, so emotions appear to play a meaningful role in major satisfaction.

It had been expected that preoccupation might have a curvilinear relationship with major satisfaction. The logic behind this prediction was that some degree of preoccupation with failure might be necessary in order for students to be motivated to do well in their studies, but very high levels of preoccupation with failure might be paralyzing and prevent students 
from performing well or recognizing their accomplishments. Perry et al. (2001) proposed further examination of preoccupation with failure as a possible factor for why students who are enthusiastic and intelligent do not complete college. Contrary to expectation, however, in the current study preoccupation with failure did not have a curvilinear relationship with major satisfaction. However, preoccupation with failure was significantly correlated with major satisfaction which supported the action control theory. This finding suggests that an overall higher level of preoccupation with failure is positively related to major satisfaction. Even though the data from the current study did not suggest a curvilinear relationship, the possibility of a curvilinear relationship between preoccupation with failure and major satisfaction should not be prematurely dismissed. It is possible that students with extremely high scores of preoccupation with failure may have already withdrawn from their studies or not commenced studies in higher education due to the paralyzing effect that high preoccupation with failure may have. The sample's mean preoccupation with failure score of 16.57 (on a scale that ranges from 12 to 24) suggests that few students at the highest levels of preoccupation were present in the sample, and this may have made it difficult to detect a curvilinear relationship in this current study.

Also, contrary to expectation with hypothesis 4 , was the finding that preoccupation with failure did not moderate the association between perceived academic control and major satisfaction. While preoccupation with failure and perceived control were each significantly related to major satisfaction when controlling for the other, the interaction between these two variables together was not significant. This finding was inconsistent with that of Perry et al. (2001), who had found that academic control had a stronger association with students' academic performance when levels of preoccupation with failure were high. Unlike Perry et al. 
(2001) who used the outcome variable of academic performance, this study measured major satisfaction which could account for the differing results. Perhaps preoccupation with failure plays a more important role in determining the associations of other variables with academic performance because failure and performance are closely linked conceptually. Those students who are preoccupied with failure may engage in specific behaviors, such as planning and studying, that have direct impacts on their performance. Preoccupation with failure's positive (but weak) association with major satisfaction might be largely the result of students' improved performance.

While the indirect effect of perceived academic control on major satisfaction via anxiety was significant, hypothesis 5 was only partially supported because the direct effect of academic control and major satisfaction also remained significant. Respondek et al. (2017) found that the emotion of anxiety fully mediated the association between perceived academic control and students' dropout intentions. The Respondek et al. (2017) sample comprised students in STEM majors, which are known to be perceived by students as highly competitive. Perhaps anxiety fully mediates the association between perceived control and academic outcomes for students in STEM fields because students with low perceived control worry that others will outperform them and set the curve for exams that is impossible for others to match. Their anxiety may interfere with performance if it distracts them or makes it difficult to focus. Among the broader sample in the current study, anxiety still appeared to play a role in determining an academic outcome (in this case, major satisfaction), but it appears that other factors beyond anxiety also influence this relationship. Additional research would be needed to identify such other factors. 
From prior research, it is known that the degree to which students' interests are related to the content of their major helps to determine major satisfaction (Schmitt et al., 2008; Tracey \& Robbins, 2006). Hypothesis 6 showed that even after controlling for the variables of year in school and interest overlap, positive and negative emotions as well as academic control still explained a significant proportion of the variance in major satisfaction. The mostly nonsignificant interaction terms between year and school and the predictor variables suggest that most of these predictors operate similarly in the determination of students' major satisfaction regardless of their year in school. However, the association of positive emotions and major satisfaction was stronger for those students who were just beginning their studies than it was for more advanced students. This finding suggests that major satisfaction may be determined, in part, by feelings such as interest, excitement, and inspiration when students are early in their college experience. Such feelings appear to remain important in determining more advanced students' major satisfaction as well, but the association weakens with more years of college under students' belts. Perhaps more advanced students are beginning to focus on the future and use their appraisals of the job market and the likelihood of finding employment to determine their major satisfaction moreso than the emotions they experience in their current classes.

Although not included as a hypothesis, it is important to consider the significant relationship between major satisfaction and intentions to remain in higher education. Prior research has shown that lower academic major satisfaction is a known risk factor for college drop-out intentions (Respondek et al., 2017; Suhre et al., 2007). If students leave college altogether or change major, this can impact additional time needed to complete new course requirements and tuition costs. While major satisfaction was also found to be significantly related to perceived academic control, positive and negative emotions, and preoccupation with 
failure, the relationship between major satisfaction and intention to remain in higher education demonstrates the importance of targeting major satisfaction to increase the chances of students completing their studies in higher education.

\section{Practical Implications}

Although there has been an increased number of students matriculating into higher education institutions, it is common for students to terminate their studies early for various reasons (Aud et al., 2012; Public Agenda, 2009). It is promising that even after accounting for preoccupation with failure, academic control, and interests overlapping with chosen major, positive academic emotions explained some of the variance in major satisfaction. Given the results of the survey, counselors and professors can provide interventions to help increase overall major satisfaction and likeliness to complete their degree. For students who display lower levels of major satisfaction, counselors and professors can target positive academic emotions. One potential approach to target emotions is Dialectical Behavioral Therapy (DBT) which is a combination both cognitive and behavioral therapies that provides skill training in four modules: mindfulness, distress tolerance, interpersonal effectiveness, and emotion regulation (Linehan, 2015). Given the relationship between positive emotions and major satisfaction, the component of emotion regulation could help students target and change unwanted negative emotions. The overall goal of emotion regulation is to help individuals identify and understand their emotions, decrease the frequency of emotions that are unwanted, decrease potential vulnerability to emotions, and decrease emotional suffering (Linehan, 2015).

Additionally, while the relationship between positive emotions and major satisfaction was significant despite year in school, the relationship was the strongest amongst freshmen and decreased with advancement within school. Higher education institutions can incorporate 
strategies that target perceived academic control and positive emotions in introductory classes. By incorporating interventions in introductory classes, the institution can ensure that all students are receiving services to help strengthen major satisfaction and target students who might need additional services related to major satisfaction. Counselors and professors can utilize emotion regulation strategies immediately with students entering higher education to help target major satisfaction that will impact students' entire career in higher education.

While both perceived academic control and preoccupation with failure were found to be related to major satisfaction, it appears that perceived control has a stronger relationship with major satisfaction and should be targeted as a possible intervention. As students enter into higher education, professors or the student counseling center can provide students with a quick survey to identify their current levels of major satisfaction and perceived control. Based on the results of the survey, counselors can provide students with enhancement interventions for perceived control, or professors can incorporate elements of attributional retraining into their courses. As proposed by Perry et al. (2005) and Respondek et al. (2017), attributional retraining could be utilized to help students reframe their understanding of their failures, and attributional retraining can help students take the approach of being responsible for their academic outcomes.

\section{Limitations and Future Research Directions}

There are some limitations due to the nature of the study. Due to the data being neither experimental nor longitudinal, causal conclusions cannot be drawn from the findings and the direction of causation cannot be inferred. It is unknown whether higher levels of preoccupation with failure and academic control lead to increased major satisfaction or whether, higher levels of academic control result in higher preoccupation with failure and academic control. 
Likewise, it is unknown whether academic emotions lead to major satisfaction or whether major satisfaction determines the emotions that students experience in their classes.

Longitudinal research could aid in drawing inferences regarding the precursor in these relations. Also, based on the demonstrated relationships between the variables in this study, future research could further determine the strength of the relationships and causation experimentally by conducting interventions that target academic control, preoccupation with failure, and emotions.

Additionally, collecting participant responses through an online questionnaire creates the potential for participants' motivation or interests to decrease while completing the survey. When motivation or interests decrease, participants may begin skipping questions, selecting random responses, or speeding through the survey which can impact the data. Two attention checks were randomly placed throughout the survey to help catch and eliminate any inaccurate data, but this does not rule out the possibility that some random responding occurs. It would be useful to collect corroborative data (e.g., physiological measures of anxiety) in future studies to help strengthen the conclusions that can be drawn from this line of research.

This study may have limited generalizability due to the total sample being recruited from a single institution which may not be representative across other higher education institutions. Future studies could explore these variables in a sample that is inclusive of twoyear, four-year, and post-baccalaureate educational settings in order to rule out the possibility of institutional idiosyncrasies. Additionally, the sample consisted primarily of individuals who identified as female. The overall sample size was sufficient for conducting the analyses, but adding gender as a moderator would have been ill-advised given the fairly small number of 
male participants. Future research should explore gender diversity more closely in order to assess if gender has an impact on these dimensions.

Based on the finding that preoccupation with failure was weakly correlated to major satisfaction, it is possible that the preoccupation with failure scale might measure something other than preoccupation, such as conscientiousness or closure. For example, preoccupation with failure may tap into behaviors related to organization or perseverance, rather than major satisfaction. Future research should explore preoccupation with failure to learn more about what the measure's scores are assessing. Additionally, future research should also further look into the relationship between perceived academic control and major satisfaction. While these variables were significantly correlated, the study found that the emotion of anxiety only partially mediated this relationship; future research should examine other variables (actual academic achievement) that might be important in understanding this relationship.

\section{Conclusions}

This study explored the relationships between preoccupation with failure, perceived academic control, and academic emotions on students' major satisfaction in order to identify possible areas to provide interventions for students to increase their major satisfaction and complete their studies in higher education. The findings of this study demonstrate significant relationships between perceived academic control and positive and negative emotions with major satisfaction. Because of this, counselors and professors should consider emotions and perceived control as possible intervention points to target major satisfaction. Interventions designed to enhance positive emotions while in classes would appear to hold the most promise early in students' education, as the positive emotions' association with major satisfaction was stronger among those just beginning their education. Anxiety appears to play some role in 
explaining the association between perceived academic control and students' major satisfaction, but future research will be needed to reveal other potential mediators. 


\section{REFERENCES}

Ahmed, W., van der Werf, G., Kuyper, H., \& Minnaert, A. (2013). Emotions, self-regulated learning, and achievement in mathematics: A growth curve analysis. Journal of Educational Psychology, 105(1), 150-161. doi:10.1037/a0030160

Ajzen, I. (1985). From intentions to actions: A theory of planned behavior. In J. Kuhl \& J. Beckmann (Eds.), Action control. Retrieved from file:///C:/Users/User/Downloads/Ajzen

.FromIntentionstoActions-TPB.1985\%20(1).pdf

Appleby, D. C. (2006). How do college freshmen view the academic differences between high school and college?, presented at Annual Meeting of the Midwestern Psychological Association, Chicago, 2006. Chicago, IL. Retrieved from http://www.apa.org/ed/precollege/ptn/2014/08/college-freshmen.aspx

Aron, A., Aron, E., \& Smollan, D. (1992). Inclusion of other in the self scale and the structure of interpersonal closeness. Journal of Personality and Social Psychology, 63(4), 596612. doi:10.1037/0022-3514.63.4.596

Artino, A. R., Holmboe, E. S., \& Durning, S. J. (2012). Control-value theory: Using achievement emotions to improve understanding of motivation, learning, and performance in medical education: AMEE Guide No. 64. Medical Teacher, 34(3). doi:10.3109/0142159x.2012.651515

Aspinwall, L. G. (1998). Rethinking the role of positive affect in self-regulation. Motivation and Emotion, 22(1), 1-32. doi:10.1023/A:1023080224401 
Aud, S., Hussar, W., Johnson, F., Kena, G., Roth, E., Manning, E., . . Zhang, J. (2012). The condition of education 2012 (NCES 2012-045). Retrieved from http://0nces.ed.gov.opac.acc.msmc.edu/pubs2012/2012045_1.pdf

Bean, J. P., (1985). Interaction effects based on class level in an explanatory model of college student dropout syndrome. American Educational Research Journal, 22(1), 35-64. doi:10.3102/00028312022001035

Beggs, J. M., Bantham, J. H., \& Taylor, S. (2008). Distinguishing the factors influencing college students' choice of major. College Student Journal, 42(2), 381-394. Retrieved from https://web-b-ebscohost-com.libproxy.lib.ilstu.edu/ehost/pdfviewer/pdfviewer? vid=5\&sid=ef2732aa-7006-445a-884a-497517bce173\%40sessionmgr104

Bowling, N. A., Eschlemna, K. J., \& Wang, Q. (2010). A meta-analytic examination of the relationship between job satisfaction and subjective well-being. Journal of Occupational and Organizational Psychology, 83, 915-934. doi:10.1348/096317909X478557

Brunborg, G. S., Pallesen, S., Diseth, A., \& Larsen, S. (2010). Preoccupation with failure affects number of study hours - Not academic achievement. Scandinavian Journal of Educational Research, 54(2), 125-132. doi:10.1080/00313831003637899

Bullock-Yowell, E., McConnell, A. E., \& Schedin, E. A. (2014). Decided and undecided students: Career self-efficacy, negative thinking, and decision-making difficulties. NACADA Journal, 34(1), 22-34. doi:10.12930/NACADA-13-016

Cherry, K. (2018). Overview of the 6 major theories of emotion. Retrieved from https://www.verywellmind.com/theories-of-emotion-2795717 
Cohen, J. (1988). Statistical Power Analysis for the Behavioral Sciences (2 ${ }^{\text {nd }}$ ed.). Retrieved from http://www.utstat.toronto.edu/ brunner/oldclass/378f16/readings/CohenPower.pdf

Dawis, R. V. (1994). The theory of work adjustment as convergent theory. In M. L. Savikas \& R. W. Lent (Eds.), Convergence in career development theories: Implications for science and practice(pp. 33-43). Palo Alto, CA: CPP Books.

Dawood, E., Ghadeer, H. A., Mitsu, R., Almutary, N., \& Alenezi, B. (2016). Relationship between test anxiety and academic achievement among undergraduate nursing students. Journal of Education and Practice, 7(2), 57-65. Retrieved from https://files.eric.ed.gov/fulltext/EJ1089777.pdf

Dweck, C. S. (2018). Reflections on the legacy of attribution theory. Motivation Science, 4(1), 17-18. doi:10.1037/mot0000095

Farmer, R., \& Sundberg, N. D. (1986). Boredom proness: The development and correlates of a new scale. Journal of Personality Assessment, 50(1), 4-17. doi:10.1207/s15327752jpa5001_2

Fishman, E. J., \& Husman, J. (2017). Extending attribution theory: Considering students' perceived control of the attribution process. Journal of Educational Psychology, 109(4), 559-573. doi:10.1037/edu0000158

Fouad, N., Cotter, E. W., \& Kantanmeni, N. (2009). The effectiveness of a career decisionmaking course. Journal of Career Assessment, 17(3), 338-347. doi:10.1177/1069072708330678

Frazier, P., Keenan, N., Anders, S., Perera, S., Shallcross, S., \& Hintz, S. (2011). Perceived past, present, and future control and adjustment to stressful life events. Journal of Personality and Social Psychology, 100(4), 749-765. doi:10.1037/a0022405 
Frazier, P., Steward, J., \& Mortensen, H. (2004). Perceived control and adjustment to trauma: A comparison across events. Journal of Social and Clinical Psychology, 23(4), 303324. doi:10.1521/jscp.23.3.303.35452

Galotti, K. M., Ciner, E. Altenbaumer, H. E., Geerts, H. J., Rupp, A. \& Woulfe, J. (2006). Decision-making styles in a real-life decision: Choosing a college major. Personality and Individual Differences, 41, 629-639. doi:10.1016/j.paid.2006.03.003

Goetz, T., Frenzel, A. C., Stoeger, H., \& Hall, N. C. (2010). Antecedents of everyday positive emotions: An experience sampling analysis. Motivation and Emotion, 34(1), 49-62. doi:10.1007/s11031.009-9152-2

Gordon, V. N., Habley, W. R., \& Grites, T. J. (2008). Academic advising: A comprehensive handbook., $2^{\text {nd }} e d$. San Francisco, CA, US: Jossey-Bass.

Hall, N. C., Chipperfield, J. G., Perry, R. P., Ruthig, J. C., \& Goetz, T. (2006). Primary and secondary control in academic development: gender-specific implications for stress and health in college students. Anxiety, Stress and Coping, 19(2), 189-210. doi:10.1080/10615800600581168

Hamm, J. M., Perry, R. P., Clifton, R. A., Chipperfield, J. G., \& Boese, G. D. (2014). Attributional retraining: A motivation treatment with differential psychosocial and performance benefits for failure prone individuals in competitive achievement settings. Basic and Applied Social Psychology, 36(3), 221-237. doi:10.1080/01973533.2014.890623

Holland, J. H. Making vocational choices: A theory of vocational personalities and work environments ( $3^{\text {rd }}$ ed.). Odessa, FL: Psychological Assessment Resources. 
Kanfer, R., Dugdale, B., \& McDonald, B. (1994). Empirical findings on the action control scale in the context of complex skill acquisition. In J. Kuhl \& J. Beckman (Eds.), Volition and personality (pp. 61-77). Seattle, WA: Hogrefe \& Huber.

Kuhl, J. (1994). A theory of action and state orientation. In J. Kuhl \& J. Beckmann (Eds.), Volition and personality (pp. 93-124). Seattle, WA: Hogfre and Huber.

Kuhl, J. \& Goschke, T. (1994). A theory of action control: Mental subsystems, modes of control, and volitional conflict-resolution strategies. In J. Kuhl \& J. Beckmann (Eds.), Volition and personality (pp. 9-46). Seattle, WA: Hogfre and Huber.

Linehan, M. M. (2015). DBT skills training manual ( $2^{\text {nd }}$ ed.). New York, NY: Guilford Press. Malle, B. F. (2011). Attribution theories: How people make sense of behavior. In D. Chadee (Ed.), Theories in social psychology. Retrieved from https://pdfs.semanticscholar .org/dbc6/ca9548099b6f2b84d1cd81f3eb13c07cde7f.pdf

McPherson, M. S., Ferguson, R. W., \& Fanton, J. F. (2016). A primer on the college student journey. Retrieved from https://www.amacad.org/multimedia/pdfs/publications/ researchpapersmonographs/PRIMER-cfue/Primer-on-the-College-Student-Journey.pdf

Menec, V. H. (1995). Volition and motivation: The effect of distracting learning conditions on students differing in action control and perceived control (Doctoral dissertation). Retrieved from file:///C:/Users/User/Downloads/Menec_Volition_and.pdf

Menec, V. H., \& Schonwetter, D. J. (1994). Action control, motivation, and academic achievement, presented at Annual Meeting of the American Educational Research Association, New Orleans, 1994. New Orleans, LA. Retrieved from https://files.eric.ed.gov/fulltext/ED368991.pdf 
Nauta, M. (2007). Assessing college students' satisfaction with their academic majors. Journal of Career Assessment, 15(4), 446-462. doi:10.1177/1069072707305762

Pekrun, R., Frenzel, A., Goetz, T., \& Perry, R. (2005). Achievement Emotions Questionnaire. User's Manual. Munich: University of Munich. Retrieved from https://www.scribd.com/doc/217451779/2005-AEQ-Manual

Pekrun, R., Frenzel, A., Goetz, T., \& Perry, R. (2007). The control-value theory of achievement emotions: An integrative approach to emotions in education. In P. A. Schutz \& R. Pekrun (Eds.), Emotion in education. Retrieved from https://pdfs.semanticscholar. org/618a/147fd937cda73c328a96b8ff5c959bbb6285.pdf

Pekrun, R., Goetz, T., Daniels, L. M., Stupnisky, R. S., \& Perry, R. P. (2010). Boredom in achievement settings: Exploring appraisal antecedents and performance outcomes of a neglected emotion. Journal of Educational Psychology, 102(3), 531-549. doi:10.1037/0278-6133.24.4.393

Pekrun, R., Goetz, T., Titz, W., \& Perry, R. P. (2002). Academic emotions in students' selfregulated learning and achievement: A program of qualitative and quantitative research. Educational Psychology, 37(2), 91-106. Retrieved from https://dnb.info/1115472046/34

Perry, R. P., Hall, N. C., \& Ruthig, J. C. (2005). Perceived (academic) control and scholastic attainment in higher education. In J. C. Smart (Ed.), Higher education: Handbook of theory and research. Retrieved from http://home.cc.

umanitoba.ca/ maach/PDFs/Perry,\%20Hall,\%20Ruthig\%20(2005).pdf 
Perry, R. P., Hladkyj, S., Pekrun, R. H., Clifton, R. A., \& Chipperfield, J. G. (2005). Perceived academic control and failure in college students: A three-year study of scholastic attainment. Res. High. Educ. 46, 535-569. doi:10.1007/s11162-005-3364-4

Perry, R. P., Hladkyj, S., Pekrun, R. H., \& Pelletier, S. T. (2001). Academic control and action control in achievement of college students: A longitudinal field study. Journal of Educational Psychology, 93(4), 776-789. doi:10.1037/0022-0663.93.4.776

Perry, R. P., Stupnisky, R. H., Daniels, L. M., \& Haynes, T. L. (2008). Attributional (explanatory) thinking about failure in new achievement settings. European Journal of Psychology Education, 23(4), 459-475. doi:10.1007/BF03172753

Peterson, C., Semmel, A., von Baeyer, C., Abramson, L. Y., Metalsky, G. I., \& Seligman, M. E. (1982). The attributional style questionnaire. Cognitive Therapy and Research, 6(3), 287-300. doi:10.1007/BF01173577

Porter, S. R., \& Umbach, P. D. (2006). College major choice: An analysis of personenvironment fit. Research in Higher Education, 47, 429-449. doi:10.1007/s11162-005$9002-3$

Public Agenda (2009, December). With their whole lives ahead of them. Retrieved from https://thechoice.blogs.nytimes.com/2009/12/09/agenda/

Respondek, L., Seufert, T., Stupnisky, R., \& Nett, U. E. (2017). Perceived academic control and academic emotions predict undergraduate university student success: Examining effects on dropout intention and achievement. Frontiers in Psychology, 8, 243, http://doi.org/10.3389/fpsyg.2017.00243 
Ruthig, J. C., Perry, R. P., Hall, N. C., \& Hladkyj, S. (2004). Optimism and attributional retraining: Longitudinal effects on academic achievement, test anxiety, and voluntary course withdrawal in college students. Journal of Applied Social Psychology, 34(4), 709-730. doi:10.111j/.1559-1816.2004.tb02566.x

Schmitt, N., Oswald, F. L., Friede, A., Imus, A., \& Merritt, S. (2008). Perceived fit with an academic environment: Attitudinal and behavioral outcomes. Journal of Vocational Behavior, 72(3), 317-335. doi:10.1016/j.jvb.2007.10.007

Schreiner, L. A. (2009). Linking student satisfaction and retention. Retrieved from https://www.ruffalonl.com/documents/shared/Papers_and_Research/2009/LinkingStude ntSatis0809.pdf

Smiley, P.A., Buttitta, K. V., Chung, S. Y., Dubon, V. X., \& Chang, L. K. (2016). Mediation models of implicit theories and achievement goals predict planning and withdrawal after failure. Motivation and Emotion, 40(6), 878-894. doi:10.1007/S11031-016-9575-5

Snead, K. J., Magal, S. R., Christensen, L. F., \& Ndede-Amadi, A. A. (2015). Attribution theory: A theoretical framework for understanding information systems success. Systemic Practice and Action Research, 28(3), 273-288. doi:10.1007/s11213-014-9328$\mathrm{x}$

Stupinsky, R. H., Perry, R. P., Hall, N. C., \& Guay, F. (2012). Examining perceived academic control level and instability as predictors of first-year college students' academic achievement. Contemporary Educational Psychology, 37(2), 81-90.

doi:10.10161j/ledpsych.2012.01.001 
Suhre, C. J. M., Jansen, P. W. A., \& Harskamp, E. G. (2007). Impact of degree program satisfaction on persistence of college students. 207-226. doi:10.1007/s10734-005-23765

Thompson, S. C. (2009). The role of personal control in adaptive functioning. In S. J. Lopez \& C. R. Snyder (Eds.), Oxford handbook of positive psychology (pp. 271-278). New York, NY, Oxford University Press.

Tobin, S. J., \& Raymundo, M. M. (2010). Causal uncertainty and psychological well-being: The moderating role of accommodation (secondary control). Personality and Social Psychology Bulletin, 36(3), 371-383. doi:10.1177/0146167209359701

Tracey, T. G., \& Robbins, S. B. (2006). The interest-major congruence and college success relation: A longitudinal study. Journal of Vocational Behavior, 69(1), 64-89. doi:10.1016/j.vb.2005.11.003

Watson, D., Clark, L. A., \& Tellegen, A. (1988). Development and validation of brief measures of positive and negative affect: The PANAS scales. Journal of Personality and Social Psychology, 54(6), 1063-1070. doi:10.1037/0022-3514.54.6.1063

Weiner, B. (1982). An attribution theory of motivation and emotion. New York: SpringerVerlag. Retrieved from file://C:/Users/User/Downloads/An_Attribution _Theory_of_Motivation_and_Emotion.pdf 